\title{
Communication
}

\section{Curcumin Enhances Cytotoxic Effects of Bortezomib in Human Multiple Myeloma H929 Cells: Potential Roles of NF-kB/JNK}

\section{Qing-Xian Bai * and Xiao-Yan Zhang}

Department of Hematology, State Center of Bone Marrow Transplantation, Xijing Hospital, Fourth Military Medical University, Xi'an 710032, China; E-Mail: zhishui2004@163.com

* Author to whom correspondence should be addressed; E-Mail: baiqingx @ sina.cn; Tel.: +86-29-84775209; Fax: +86-29-84775209.

Received: 9 March 2012; in revised form: 31 March 2012 / Accepted: 11 April 2012 /

Published: 16 April 2012

\begin{abstract}
Combined curcumin and PS-341 treatment has been reported to enhance cytotoxicity and minimize adverse effects through ERK and p38MAPK mechanisms in human multiple myeloma cells. However, whether JNK plays similar role in this process remains unclear. In the present study, we found combined treatment altered NF- $\kappa \mathrm{B}$ p65 expressions and distributions in multiple myeloma H929 cells. Western blot analysis showed combined treatment inactivated NF- $\kappa$ B while activated JNK signaling. Pre-treatment with JNK inhibitor SP600125 could attenuate NF- $\mathrm{KB}$ inactivation and restored H929 cells' survival. These results suggested that curcumin might enhance the cytotoxicity of PS-341 by interacting with $\mathrm{NF}-\kappa \mathrm{B}$, at least in part, through JNK mechanism.
\end{abstract}

Keywords: curcumin; PS-341; multiple myeloma; NF-кB; JNK

\section{Introduction}

Multiple myeloma is a kind of plasma cell-derived human cancer that causes multiple bone lesions and disturbs the production of normal blood cells. It is the second most prevalent hematologic malignancy after non-Hodgkin's lymphoma [1]. Complications of untreated or poorly controlled multiple myeloma can be serious and it is generally thought to be an incurable disease, but remissions may be induced with steroids, chemotherapy, radiotherapy, and stem cell transplants. Bortezomib, (PS-341, Velcade ${ }^{\circledR}$ ) specifically targeting the ubiquitin-proteasome pathway, is the first defined therapeutic proteasome inhibitor approved by FDA for treating refractory, advanced or rapidly 
relapsed multiple myeloma [2]. It is well documented the mechanism of action for PS-341 lies in its highly affinity and specificity to the catalytic site of the $26 \mathrm{~S}$ proteasome. There is also increasing evidence that the lethal actions of PS-341 may be related to inactivation of NF- $\kappa$ B pathway [3-5].

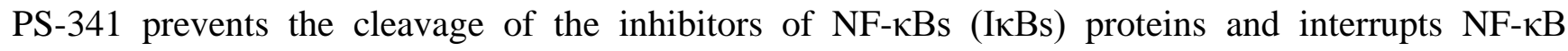
translocation from the cytoplasm to the nucleus, therefore inhibiting proliferation and inducing apoptosis [6]. Although PS-341 has been recommended as the first-line therapy for multiple myeloma, the single-agent activity of PS-341 has been limited [7,8]. The PS-341-based clinical therapeutic strategy for multiple myeloma usually includes other chemotherapeutics, such as adriamycin, decaspray, and thalidomide.

Curcumin is a major active ingredient derived from the plant Curcuma longa L. Extensive studies during the past two decades have well documented a wide range of biological activities of curcumin, including anti-cancer properties. Epidemiological evidence also suggests that people who eat curcumin-rich diets have a lower incidence of human cancers. It is noted that curcumin induces

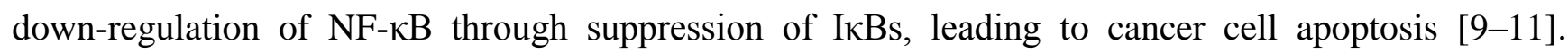
Meanwhile, the chemosensitizing effect of curcumin has been reported in cancers of the breast, colon, pancreas, gut, liver, lung, prostate, brain, and in multiple myeloma, lymphoma and leukemia [12,13]. Interestingly, it is noted that curcumin shows a synergistic effect when combined with PS-341. We and others have recently reported that curcumin enhances the cytotoxic effect of PS-341 in human multiple myeloma cells through regulating NF- $\mathrm{B}$ and Bcl-2 family proteins expressions [14-17]. These beneficial merits develop curcumin as a potential adjuvant agent to standard chemotherapy, in particular for highly malignant, refractory, and relapsed cancers.

Mitrogen-activated protein kinases (MAPKs) family consists of extracellular signal-regulated kinase (ERK), p38MAPK, and c-Jun $\mathrm{NH}_{2}$-terminal kinase (JNK), which participated in numerous physiological processes. Expanding studies indicate that ERK and p38MAPK signalings are implicated in manipulating NF- $\mathrm{KB}$ and its downstream targets as a response to curcumin in human multiple myeloma cells. However, the distinct roles of JNK in this process remain to be investigated $[15,18,19]$. To address these questions, we therefore explored potential roles of JNK in curcumin-mediated NF- $\mathrm{B}$ signal in human multiple myeloma H929 cells.

\section{Results and Discussion}

\subsection{Curcumin and PS-341 Altered Expression and Distribution Profiles of NF- $\kappa B$ p65}

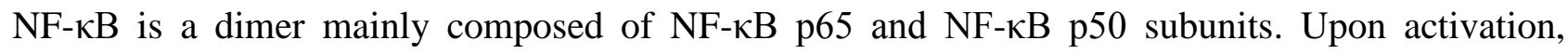
$\mathrm{NF}-\kappa \mathrm{B}$ p65 was released from the NF- $\kappa \mathrm{B}$ transcription complex, bound to corresponding DNA and regulated the transcription of specific genes. Therefore, NF- $\mathrm{B}$ p65 is an inducible and functional subunit of NF- $\kappa \mathrm{B}$ transcription complex, which provides the gene's regulatory activities. NF- $\kappa \mathrm{B}$ p65 in H929 cells receiving various treatments was visualized by immunoflurencent staining (Figure 1).

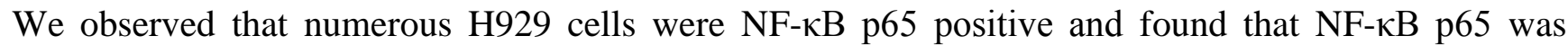
distributed in the whole nucleus (as the arrow head indicated). The proportions of NF- $\mathrm{BB}$ p65-expressing cells seemed to decrease in H929 cells supplemented with curcumin or PS-341. Combined curcumin and PS-341 treatment notably decreased the amount of NF- $\kappa$ B p65 positive H929 


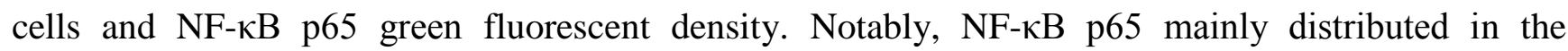
periphery of the nucleus after combined treatment (as the arrow indicated).

Figure 1. Immunoflurencent staining showing the expression and distribution of $\mathrm{NF}-\kappa \mathrm{B}$ p65 in response to curcumin with or without PS-341. Cell nucleus were stained with DAPI and visualized by blue fluorescence. NF- $\kappa \mathrm{B}$ p 65 was stained with corresponding antibodies and visualized by green fluorescence. The distribution of NF- $\kappa \mathrm{B}$ p65 within the cell nucleus was indicated by the arrow heads and arrows in the enlarged version.

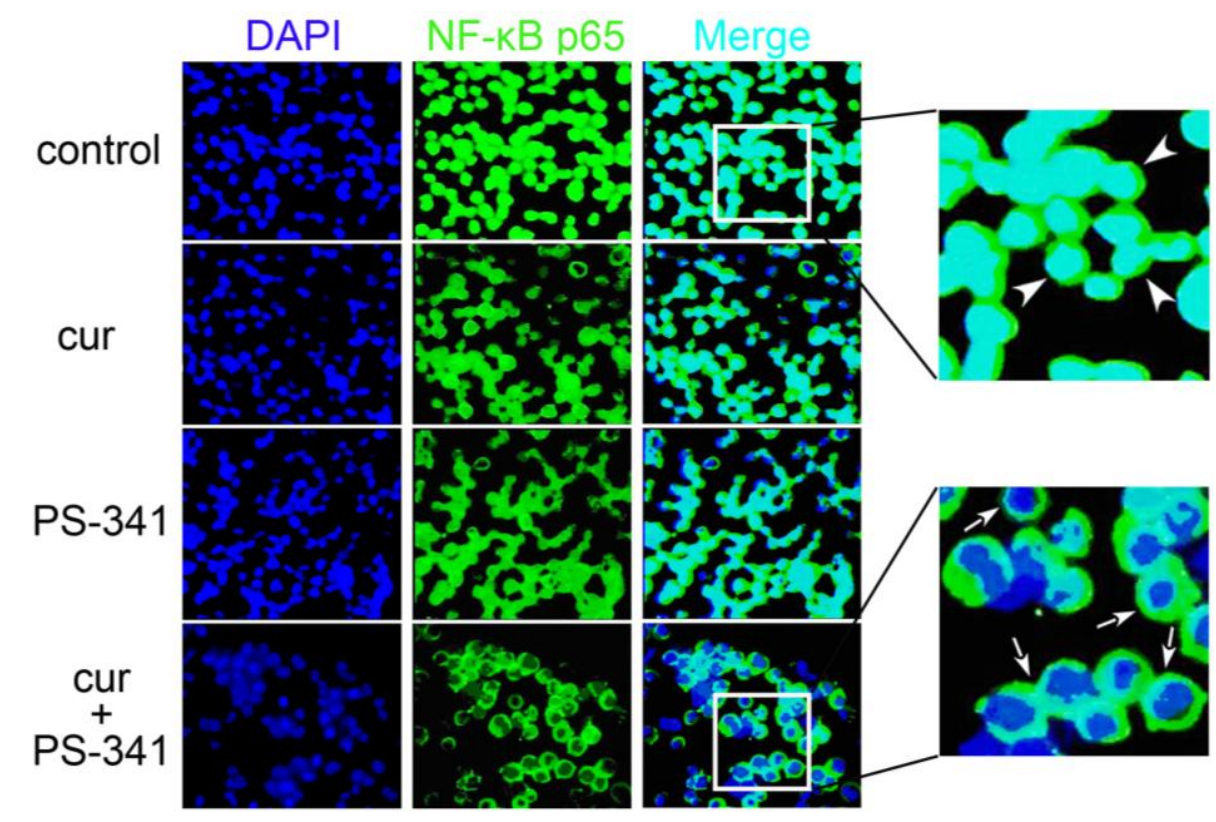

\subsection{Curcumin and PS-341 Stabilized IאB through JNK Mechanism}

As the expressions and activities of NF- $\kappa \mathrm{B}$ p65 are mainly regulated by $\mathrm{I} \kappa \mathrm{B}$, Western blot was employed to analyze the content of $\mathrm{I} \kappa \mathrm{B}$ and NF- $\kappa \mathrm{B}$ p 65 after the indicated treatments. Incubation with

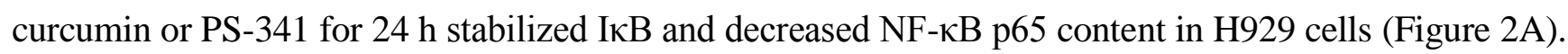
Combined treatment exerted a remarkable effect on the stabilization of I $\mathrm{B}$, which in turn inhibited the expression and transcription activities of NF- $\mathrm{KB}$ p65.

ERK and p38MAPK have been reported to contribute to curcumin- and PS-341-mediated IкB stabilization and NF- $\kappa \mathrm{B}$ expressions in human multiple myeloma cells in vivo and in vitro. Blockage of ERK and p38MAPK signaling restored NF- $\kappa$ B activation and promoted I $\kappa$ B degradation $[15,18,19]$. However, whether or not the JNK mechanism plays similar roles in the presence of curcumin and PS-341 is still unclear. We therefore investigated JNK expressions after the indicated treatment. As the activation of JNK requires phosphorylation (p-JNK), it was observed that treatment with curcumin or PS-341 singularly did not significantly affect JNK phosphorylation. Similarly to previous studies, combined curcumin and PS-341 treatment markedly promoted the expression of p-JNK compared with the baseline (Figure 2A). However, pre-treatment with the JNK specific inhibitor SP600125 attenuated NF- $\kappa$ B p65 inactivation and JNK phosphorylation (Figure $2 B$ ). Herein we raise the hypothesis that the mechanism of action for curcumin in combination with PS-341 treatment on NF- $\kappa$ B signaling might be JNK-dependent. 
Figure 2. Western blot analysis of $\mathrm{I} \kappa \mathrm{B}, \mathrm{NF}-\kappa \mathrm{B}$ p65, p-JNK and JNK. (A) H929 cells received curcumin with or without PS-341 treatments. Combined treatment significantly activated JNK signaling and inhibited NF- $\mathrm{B}$ activity; (B) Pretreatment with JNK inhibitor SP600125 inhibits JNK phosphorylation, and abolished effects of combined treatment on $\mathrm{NF}-\kappa \mathrm{B}$ activity. $\beta$-actin was used for equal loading.

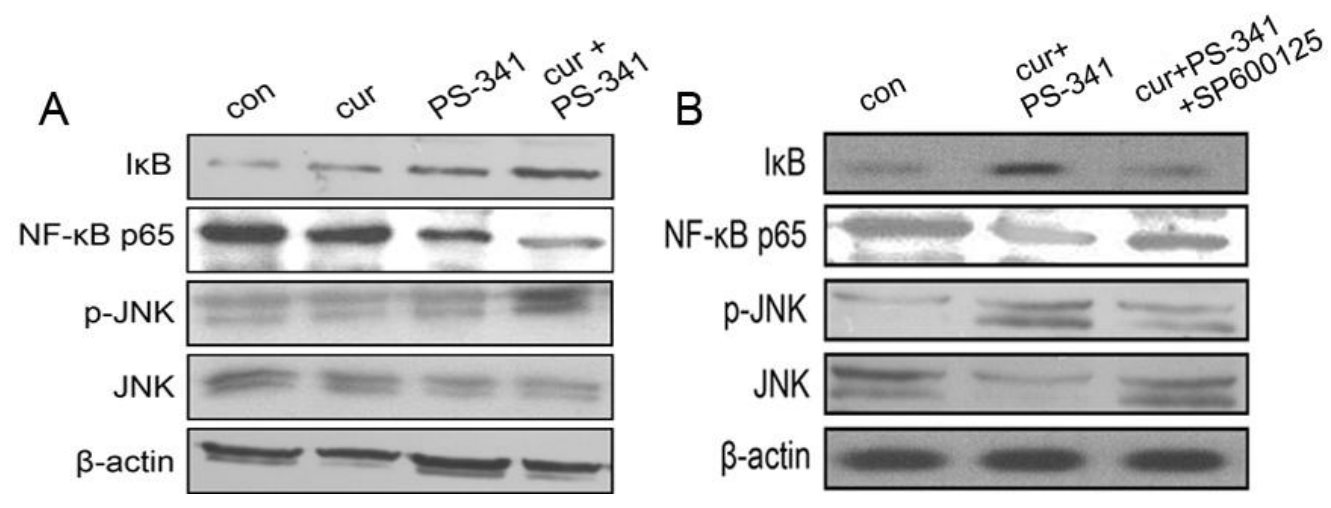

\subsection{Blockage of JNK Restored H929 Cells Survival}

In order to test this idea, DAPI and PI fluorescent stainings were performed to determine cell viability and apoptosis. The blue fluorescence of DAPI represents the cell nucleus. Because PI cannot penetrate the livingcells, the PI fluorescence is only observed in the necrotic and dead cells. There were few PI positive H929 cells without curcumin and PS-341 treatment (Figure 3). However, combined curcumin and PS-341 treatment provoked remarkable H929 cell death compared with the baseline. As expected, pre-treatment with SP600125 decreased the numbers of PI positive cells. These results indicated that the JNK inhibitor SP600125 attenuated the cytotoxicity of combined treatment.

Figure 3. DAPI and PI double staining of H929 cells. Cell nucleus was visualized by DAPI. Cells undergoing necrosis were stained by PI. Cells were observed at $\times 200$ magnification, scale bar $=20 \mu \mathrm{m}$.

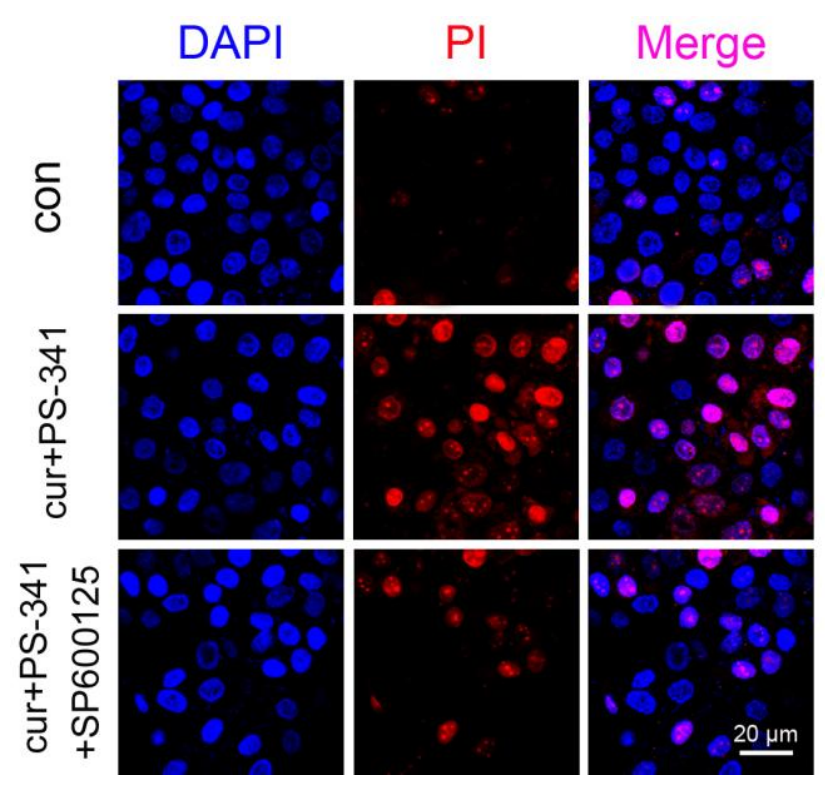


We next evaluated pre-treatment with SP600125 on H929 cells apoptosis by flow cytometry. Less than $2 \%$ of cells underwent apoptosis without any treatments. Combined curcumin and PS-341 treatment led to profound apoptotic cell death compared with the baseline. However, pre-treatment with SP600125 reduced the apoptotic ratio from $(40.62 \pm 4.619) \%$ to $(5.32 \pm 1.155) \%$, suggesting combined treatment on the NF- $\mathrm{kB}$ signaling and H929 cells apoptosis was JNK-dependent (Figure 4).

Figure 4. Flow cytometry analysis of cell apoptosis with or without SP600125 pre-treatment. $* P<0.05$ vs. control or SP600125 pretreatment.
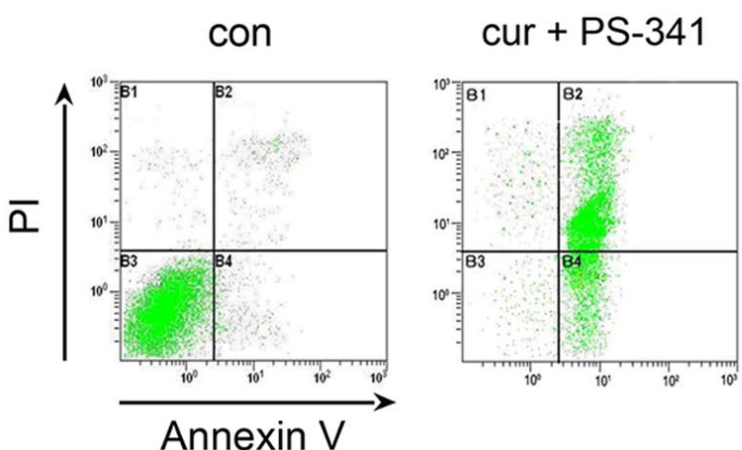

Annexin V
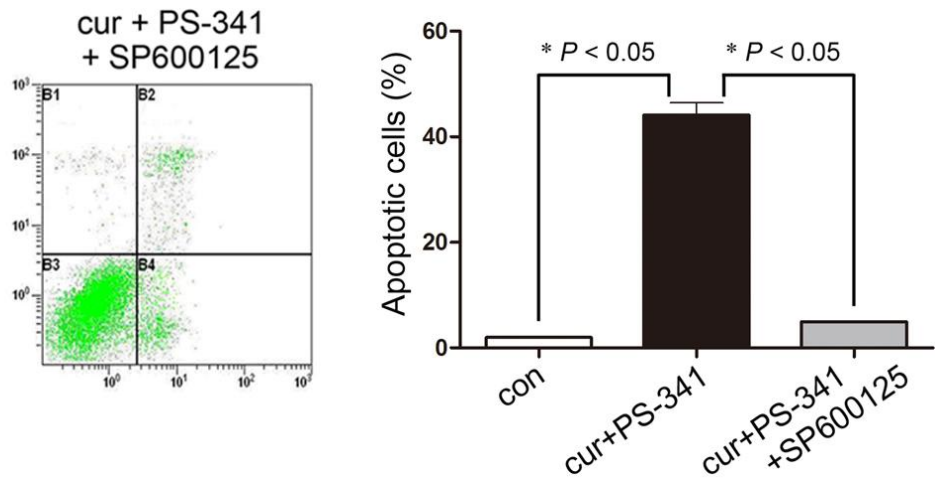

\section{Experimental Section}

\subsection{Reagents}

Medicine: Curcumin was purchased from Sigma (St Louis, MO, USA). PS-341was purchased from Millennium Pharmaceuticals (Cambridge, MA, USA). SP600125 was purchased from Biomol Research Laboratories (Plymouth Meeting, PA). Curcumin, PS-341 and SP600125 were dissolved in DMSO $(1 \mathrm{mM})$ as stock solutions, stored at $-20{ }^{\circ} \mathrm{C}$, and diluted to indicate concentration with culture medium.

Materials: Penicillin, streptomycin, fetal bovine serum and RPMI 1640 were purchased from Invitrogen (Carlsbad, CA, USA). Antibodies against I $\mathrm{B}, \mathrm{NF}-\kappa \mathrm{B}$ p65, JNK, p-JNK were purchased from Santa Cruz (Santa Cruz, CA, USA). Rabbit anti- $\beta$-actin antibody was purchased from Abcam (Cambridge, MA, USA).

\subsection{Cell Culture}

Human multiple myeloma H929 cells were obtained from American Type Culture Collection, and cultured in RPMI 1640 medium supplemented with 10\% FBS, penicillin (100 U/mL) and streptomycin $(100 \mu \mathrm{g} / \mathrm{mL})$ in an atmosphere with $5 \% \mathrm{CO}_{2}$ at $37{ }^{\circ} \mathrm{C}$. In all experiments, exponentially growing cells were used.

\subsection{Fluorescent Immunocytochemistry of $N F-\kappa B$ p65}

After indicated treatments, cells were fixed with $4 \%$ paraformaldehyde in PBS for 20 min and permeabilized with $0.5 \%$ Trixon $\mathrm{X}-100$ for $15 \mathrm{~min}$. To identify the cell nucleus, cells were

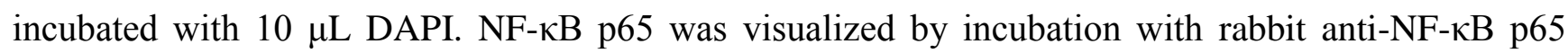


antibody followed by corresponding FITC-labeled secondary antibody. Cells were then viewed and photographed. DAPI and FITC fluorescence were immediately observed under a fluorescent microscope (Olympus, Japan).

\subsection{Assay of I $\kappa B, N F-\kappa B$ p 65 and $J N K$}

$\mathrm{I} \kappa \mathrm{B}, \mathrm{NF}-\kappa \mathrm{B} \mathrm{p} 65, \mathrm{JNK}$ and $\mathrm{p}-\mathrm{JNK}$ protein contents in response to various treatments were determined by Western blot as described previously [14-17].

\subsection{Analysis of JNK in H929 Cell Apoptosis}

To investigate distinct roles of JNK in combined treatments mediated H929 cell apoptosis, SP600125, a specific JNK inhibitor was used to block the phosphorous and activity of JNK. Cells were pre-treated with $5 \mu \mathrm{M}$ SP600125 (SP600125 was not cytotoxic below $10 \mu \mathrm{M}$ ) for $1 \mathrm{~h}$ followed by combined curcumin and PS-341 treatment. JNK, p-JNK, I $\mathrm{B}$ and NF- $\kappa \mathrm{B}$ p65 protein contents were determined by Western blot as have described. For cell viability assay, H929 cells were stained by DAPI and PI. The necrotic and dead H929 cells were observed at $\times 200$ magnification under a fluorescent microscope (Olympus, Japan). Quantitatively analysis of cell apoptosis was determined by flow cytometry as have described.

\subsection{Statistical Analysis}

Data are expressed as means \pm SD. Differences between groups were analyzed by one-way analysis of variance (ANOVA) followed by LSD post hoc test using SPSS statistical software (SPSS, Inc., Chicago, IL). Significance was considered at $* P<0.05$.

\section{Conclusion}

In the present study, we found that curcumin as a chemosensitizer could enhance the cytotoxic effect of PS-341. Combined curcumin and PS-341 treatment interacts with NF- $\kappa$ B signaling and alters NF- $\kappa$ B p65 expressions and distributions. Pre-treatment with JNK inhibitor SP600125 restored H929 cells' survival and attenuated NF- $\kappa \mathrm{B}$ inactivation as a response to curcumin and PS-341. These results suggest the cytotoxic effect of combined treatment on H929 cells attributes to interaction with NF- $\mathrm{BB}$ signaling, and this mechanism might be partly JNK-dependent.

\section{Acknowledgments}

The present study was supported by grants National Natural Science Foundation of China (30070323).

\section{References}

1. Kyle, R.A.; Rajkumar, S.V. Multiple myeloma. N. Engl. J. Med. 2004, 351, 1860-1873.

2. Adams, J.; Kauffman, M. Development of the proteasome inhibitor Velcade (Bortezomib). Cancer Invest. 2004, 22, 304-311. 
3. Almond, J.B.; Cohen, G.M. The proteasome: A novel target for cancer chemotherapy. Leukemia 2002, 16, 433-443.

4. Ling, Y.H.; Liebes, L.; Ng, B.; Buckley, M.; Elliott, P.J.; Adams, J.; Jiang, J.D.; Muggia, F.M.; Perez-Soler, R. PS-341, a novel proteasome inhibitor, induces Bcl-2 phosphorylation and cleavage in association with G2-M phase arrest and apoptosis. Mol. Cancer Ther. 2002, 1, 841-849.

5. Dai, Y.; Rahmani, M.; Grant, S. Proteasome inhibitors potentiate leukemic cell apoptosis induced by the cyclin-dependent kinase inhibitor flavopiridol through a SAPK/JNK- and NF- $\kappa B-d e p e n d e n t$ process. Oncogene 2003, 22, 7108-7122.

6. Shah, J.J.; Orlowski, R.Z. Proteasome inhibitors in the treatment of multiple myeloma. Leukemia 2009, 23, 1964-1979.

7. Kouroukis, C.T.; Belch, A.; Crump, M.; Eisenhauer, E.; Gascoyne, R.D.; Meyer, R.; Lohmann, R.; Lopez, P.; Powers, J.; Turner, R.; et al. Flavopiridol in untreated or relapsed mantle-cell lymphoma: Results of a phase II study of the National Cancer Institute of Canada Clinical Trials Group. J. Clin. Oncol. 2003, 21, 1740-1745.

8. Holkova, B.; Grant, S. Combining proteasome with cell cycle inhibitors: A dual attack potentially applicable to multiple hematopoietic malignancies. Expert Rev. Hematol. 2011, 4, 483-486.

9. Singh, S.; Aggarwal, B.B. Activation of transcription factor NF-kappa B is suppressed by curcumin (diferuloylmethane). J. Biol. Chem. 1995, 270, 24995-25000.

10. Hussain, A.R.; Ahmed, M.; Al-Jomah, N.A.; Khan, A.S.; Manogaran, P.; Sultana, M.; Abubaker, J.; Platanias, L.C.; Al-Kuraya, K.S.; Uddin, S. Curcumin suppresses constitutive activation of nuclear factor-kappa B and requires functional Bax to induce apoptosis in Burkitt's lymphoma cell lines. Mol. Cancer Ther. 2008, 7, 3318-3329.

11. Lee, K.H.; Chow, Y.L.; Sharmili, V.; Abas, F.; Alitheen, N.B.M.; Shaari, K.; Israf, D.A.; Lajis, N.H.; Syahida, A. BDMC33, a curcumin derivative suppresses inflammatory responses in macrophage-like cellular system: Role of inhibition in $\mathrm{NF}-\mathrm{\kappa B}$ and MAPK signaling pathways. Int. J. Mol. Sci. 2012, 13, 2985-3008.

12. Patel, B.B.; Sengupta, R.; Qazi, S.; Vachhani, H.; Yu, Y.; Rishi, A.K.; Majumdar, A.P. Curcumin enhances the effects of 5-fluorouracil and oxaliplatin in mediating growth inhibition of colon cancer cells by modulating EGFR and IGF-1R. Int. J. Cancer 2008, 122, 267-273.

13. Aggarwal, B.B.; Shishodia, S.; Takada, Y.; Banerjee, S.; Newman, R.A.; Bueso-Ramos, C.E.; Price, J.E. Curcumin suppresses the paclitaxel-induced nuclear factor-kappaB pathway in breast cancer cells and inhibits lung metastasis of human breast cancer in nude mice. Clin. Cancer Res. 2005, 11, 7490-7498.

14. Sung, B.; Kunnumakkara, A.B.; Sethi, G.; Anand, P.; Guha, S.; Aggarwal, B.B. Curcumin circumvents chemoresistance in vitro and potentiates the effect of thalidomide and bortezomib against human multiple myeloma in nude mice model. Mol. Cancer Ther. 2009, 8, 959-970.

15. Park, J.; Ayyappan, V.; Bae, E.K.; Lee, C.; Kim, B.S.; Kim, B.K.; Lee, Y.Y.; Ahn, K.S.; Yoon, S.S. Curcumin in combination with bortezomib synergistically induced apoptosis in human multiple myeloma U266 cells. Mol. Oncol. 2008, 2, 317-326.

16. Zhang, X.Y.; Bai, Q.X.; Huang, G.S.; Zhao, H.; Chen, J.J.; Yang, L.J. Effect of curcumin in combination with bortezomib on proliferation and apoptosis of human multiple myeloma cell line H929 and its mechanism. Zhongguo Shi Yan Xue Ye Xиe Za Zhi 2011, 19, 684-688. 
17. Mujtaba, T.; Kanwar, J.; Wan, S.B.; Chan, T.H.; Dou, Q.P. Sensitizing human multiple myeloma cells to the proteasome inhibitor bortezomib by novel curcumin analogs. Int. J. Mol. Med. 2012, 29, 102-106.

18. Liang, J.; Saad, Y.; Lei, T.; Wang, J.; Qi, D.; Yang, Q.; Kolattukudy, P.E.; Fu, M. MCP-induced protein 1 deubiquitinates TRAF proteins and negatively regulates JNK and NF- $\mathrm{BB}$ signaling. J. Exp. Med. 2010, 207, 2959-2973.

19. Hsieh, I.N.; Chang, A.S.; Teng, C.M.; Chen, C.C.; Yang, C.R. Aciculatin inhibits lipopolysaccharide-mediated inducible nitric oxide synthase and cyclooxygenase-2 expression via

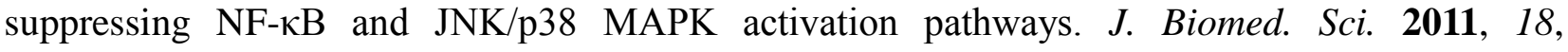
doi:10.1186/1423-0127-18-28.

(C) 2012 by the authors; licensee MDPI, Basel, Switzerland. This article is an open access article distributed under the terms and conditions of the Creative Commons Attribution license (http://creativecommons.org/licenses/by/3.0/). 